\title{
Mechanisms of self-renewal in hematopoietic stem cells
}

\author{
Zhao Wang ${ }^{1} \cdot$ Hideo Ema ${ }^{1}$
}

Received: 25 November 2015 / Accepted: 30 November 2015 / Published online: 12 December 2015

(C) The Japanese Society of Hematology 2015

\begin{abstract}
A large number of studies have shown that quiescence is essential for hematopoietic stem cells (HSCs) to maintain their number and function. Otherwise, HSCs are exhausted or damaged by various substances. We need to understand how the quiescent state is maintained in HSCs, how HSCs are driven into the cell cycle, and how HSCs return to the quiescent state. We also need to understand how cycling HSCs make the decision whether to selfrenew. A number of molecules have been reported as candidate regulators of these events in HSCs. In this review, we focus on the HSC niche, the cytokine network, and associated transcription factors; and then discuss to what extent we can currently understand these critical issues in stem cell biology.
\end{abstract}

Keywords Hematopoietic stem cells · Quiescence ·

Self-renewal $\cdot$ Differentiation $\cdot$ Niche

\section{Introduction}

Hematopoietic stem cells (HSCs) are able to both selfrenew and differentiate into all blood lineages. It has been long thought that HSCs are required for the development, maintenance, and regeneration of the hematopoietic system. A completely new view of hematopoiesis was provided recently by Camargo and his colleagues [1]. A new marking method using Sleeping Beauty transposase permitted

Hideo Ema

hema@ihcams.ac.cn

1 Institute of Hematology and Blood Diseases Hospital, Chinese Academy of Medical Sciences and Peking Union Medical College, 288 Nanjing Rd, Tianjin 300020, China the in vivo clonal tracking of HSCs and hematopoietic progenitor cells (HPCs) in physiological conditions. Surprisingly, myeloid, B-lymphoid, and T-lymphoid lineages seem to be independently maintained by HPCs in adult mice. Of particular interest is that granulopoiesis is supplied mainly by relatively short-lived HPCs, but not by HSCs with multilineage reconstitution potential. Myelopoiesis is the major function in the bone marrow. Repopulating common myeloid progenitors (rCMP) $[2,3]$ may participate in this transient but massive blood production.

In contrast, HSCs are not often used in normal hematopoiesis and are most likely preserved for emergent hematopoiesis such as after transplantation, blood loss, or infection. Dormant HSCs, which differ from regular HSCs, have been described [4]. All HSCs could be a dormant type. Most HSCs and HPCs are in the G0 state, but divide approximately once per month [5-7]. It is likely that both HSCs and HPCs randomly enter the cell cycle from time to time [8]. HPCs may undergo self-renewal to expand their pool during aging [7], whereas HSCs may undergo either self-renewal or differentiation for a limited time. As a result, the number of HSCs slightly increases during aging [7]. If HSCs undergo differentiation division, they can contribute to long-term hematopoiesis including a lymphoid lineage. Otherwise, HSCs may not contribute to active hematopoiesis at all [1]. The in vivo clonal behaviors of HPCs and HSCs are illustrated in Fig. 1.

HSCs are regulated by two important mechanisms. One is the G0 phase control, and the other is fate determination (either self-renew or differentiation). These events occur in bone marrow niches. A number of studies reported a variety of candidate niche cells. It is now important to study their functional roles in HSC regulation. Particularly, we need to understand what type of extracellular signals control the HSC G0 state and their fate determination. Our 

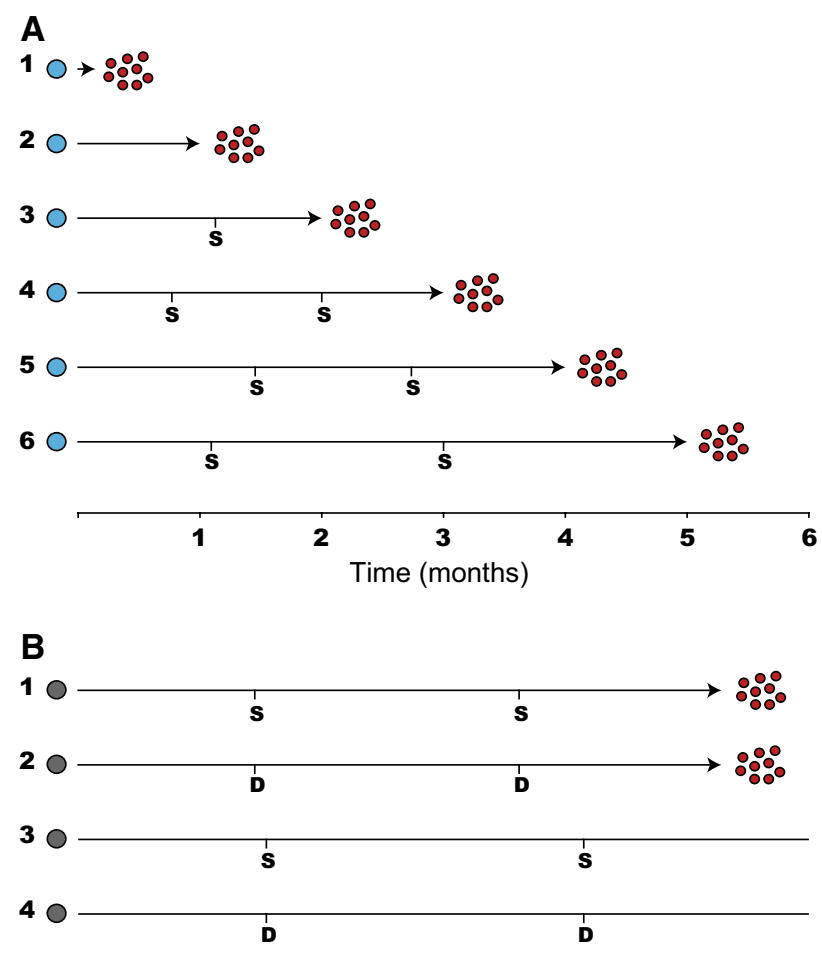

50

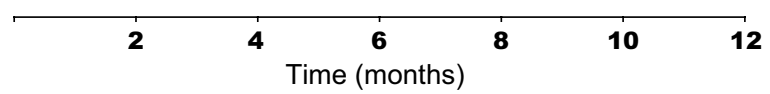

Fig. 1 Normal hematopoiesis maintained by HPCs but not HSCs. Clonal behaviors of HPCs and HSCs are illustrated based on our interpretation of published data [1]. a Most HPCs are in the G0 state but differentiate into mature blood after varied periods of time. After a large amount of blood production, HPCs are exhausted. Before their commitment to differentiation, HPCs may self-renew (S) intermittently. Most HPCs are myeloid HPCs (perhaps some are corresponding to rCMP) independent of B- and T-lymphoid progenitors. Presumably, clones 1-6 randomly contribute to active hematopoiesis intermittently. b Most HSCs are in the G0 state and enter the cell cycle, resulting in selfrenewal (clones 1,3) or differentiation (clones 2,4) only a few times. HSCs may contribute to hematopoiesis after a long G0 time (clones 1, 2) or may not contribute to hematopoiesis at all (clones 3-5). Clones $3-5$ are detectable only by transplantation experiments

long-term interest in stem cell biology is to understand how self-renewal is regulated in HSCs. In this review, we also focus on cytokines as extracellular signals and transcription factors as intracellular molecules.

\section{Methods to detect self-renewal in HSCs}

To unveil the mechanism of self-renewal, the method used to detect the self-renewal capacity is crucial. The long-term competitive repopulating assay is the gold standard. We previously decided that the minimum follow-up period is 4 months after transplantation. However, we have recently revised this stance [3]. We now consider that 1 year or longer is necessary to detect long-term (LT)-HSCs appropriately. Recipient mice sometimes die for unknown reasons before 1 year. In that case, secondary transplantation is performed so that we can ensure sufficient survival duration of recipient mice to detect LT-HSCs and also confirm their self-renewal potential [3]. In data interpretation, we need to pay more attention to the nature of competitive repopulation. Repopulating activity is always measured relative to that of competitor cells [9]. It is difficult to know the absolute repopulating activity.

Based on competitive repopulation assays, two types of units are often used. One is repopulating units (RUs) [9]. The other is competitive repopulation units (CRUs) [10]. These units should be distinguished from one another [11]. The RU indicates a relative amount of activity, whereas CRU indicates the number of HSCs. To calculate fold increase or decrease between two groups to be compared, both units are useful. RUs can be easily applied to serial transplantation. Usually, RUs depend on CRUs, but this is not always the case. For instance, in some gene knockout mice, RUs/cell (mean activity per stem cell [11]) is increased [12]. It should be kept in mind that competitive repopulation assays may not be useful when HSCs have homing or engraftment defect [13].

\section{Niche cells regulating HSCs}

Stem cells reside in a specialized microenvironment termed the "niche", which may be a functional unit important for their development, maintenance, regeneration, and protection from various damages $[14,15]$. Although the concept of the niche was originally proposed in the 1970s by Schofield [16], only in the last decade has significant progress been made thanks to technological advances such as those in conditional gene deletion and bone marrow imaging [17]. Multiple cell types have been identified as niche cells supporting HSCs (Fig. 2). Candidate niche cells are perivascular cells, endothelial cells, CXCL12 abundant reticular (CAR) cells, osteoblasts, neurons, and others [18]. Some cell populations such as CAR cells and perivascular cells may overlap one another because these cells can be developmentally related. It was reported that CAR cells contain preosteoblasts as the major component and are similar to Leptin receptor expressing (Lepr+) stromal cells but different from Nestin+ perivascular cells [18].

Recent studies have shown that perivascular stromal cells play a critical role in the regulation of HSCs and these stromal cells localize near both HSCs and endothelial cells [19]. These cells usually express high levels of CXCL12 and stem cell factor (SCF). By inserting green fluorescent protein (GFP) into the endogenous $S c f$ locus, 


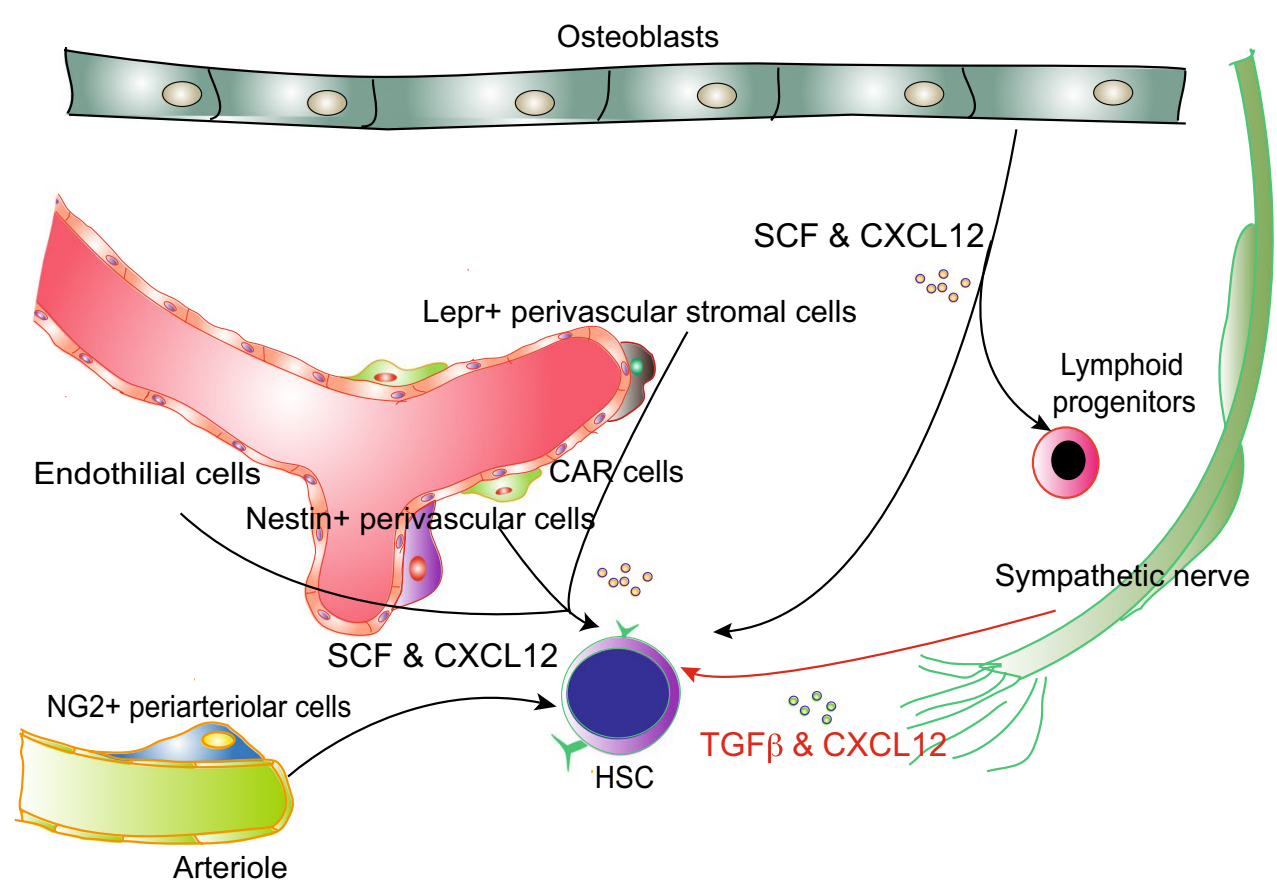

Fig. 2 Niche cells. There are a variety of candidate niche cells, including osteoblasts, endothelial cells, CAR cells, Nestin+ perivascular cells, Lepr+ perivascular stromal cells, NG2+ periarteriolar

SCF expression was detected primarily in perivascular and endothelial cells rather than in endosteum or bonelining cells, suggesting that perivascular cells, as a niche component, are crucial in HSC regulation [20]. Various genetically modified mice models were used to identify perivascular cell markers to clarify specific cell types in the niche [17]. One candidate niche cell type is Lepr+ perivascular stromal cells, which also express CXCL12, SCF, and alkaline phosphatase (a marker of mesenchymal cells). Deleting $S c f$ from Lepr+ perivascular stromal cells will reduce the HSC number in the bone marrow but significantly increase the HSC frequency in the spleen, indicating that Lepr+ perivascular stromal cells retain a constant number of HSCs in the bone marrow [20].

Nestin+ perivascular cells are additional candidate niche cells of the mesenchymal cell type, which express $\operatorname{PDGFR} \alpha$ and CD51 [21]. By crossing the Cre-recombinase-inducible diphtheria toxin receptor mice (iDTR) with Nestin-Cre mice, researchers could selectively eliminate Nestin + perivascular cells by treating the mice with tamoxifen and diphtheria toxin. When the depletion occurred, the number of phenotypically identified HSCs was rapidly reduced in the bone marrow, and this was accompanied by an increased number of HSCs in the spleen and a decreased homing capacity upon transplantation. These data suggest that Nestin+ perivascular cells play a role in the cells, and nerve cells. SCF and CXCL12 positively regulate HSCs. TGF- $\beta$ negatively regulates HSCs

maintenance of HSCs in the bone marrow to avoid excessive mobilization towards extra-medullary sites [22].

The availability of numerous conditional knockout mice for evaluating niche cell types has provided extensive flexibility in experimental design. However, we must remain cautious because gene-specific does not equate to cell-specific. Some gene expression may cover a range of cell types. For example, Nestin + cells are heterogeneous in developing embryos, where they divide into endothelial and non-endothelial Nestin+ cells. After birth, Nestin+ cells become more diverse, and their sub-populations cover a range from osteoblasts to endothelial lineages [23]. Lepr+ stromal cells are thought to be a perivascular stromal cell type [24]. However, fate-mapping studies show that Lepr+ cells are also a major source of adipocytes in the bone marrow [19]. Thus, the utility of gene targeting in the study of niche cells remains limited, which must be considered in the interpretation of these studies.

Apart from perivascular stromal cells, endothelial cells are a crucial niche component. Although CXCL12 is also expressed in endothelial cells [25], the deletion of CXCL112 from these cells resulted in a modest loss of long-term repopulating activity in HSCs [26]. When Scf was conditionally deleted from endothelial cells, the frequency of LT-HSCs in the bone marrow was significantly reduced, whereas the blood cell count and bone marrow cellularity remained unchanged [20]. This study showed 
that SCF expression in endothelial cells was required to maintain HSCs in the bone marrow. Kobayashi et al. used an Akt constitutive activation model to investigate the relationship between endothelial cells and HSCs at the molecular level. They found that Akt activation in endothelial cells, through the recruitment of mammalian target of rapamycin (mTOR), up-regulated specific angiocrine factors to expand LT-HSCs [27]. These studies support the role of endothelial cells in the maintenance of HSCs. Distinct from sinusoid endothelial cells, $\mathrm{NG} 2+$ perivascular cells sheathing small arterioles were shown to have the capacity to maintain HSC quiescence. The depletion of NG2+ cells induced HSC cycling and reduced the frequency of long-term repopulating HSCs in the bone marrow. Interestingly, cycling HSCs moved from $\mathrm{NG} 2+$ periarteriolar cells to Lepr+ perisinusoidal cells [28].

Two research groups independently identified osteoblasts as the first niche component a decade ago [29, 30]. Osteoblasts were thought to be involved in supporting HSC maintenance, self-renewal, and proliferation [31]. The ablation of osteoblasts led to a loss of HSCs in the bone marrow with enhanced extra-medullary hematopoiesis [32]. However, when CXCL12 was selectively deleted from osteoblasts, Link et al. observed a loss of B-lymphoid progenitors rather than the loss of HSCs [26]. A similar finding was reported by Morrison's group [24]. The analysis of $S c f$ conditional knockout in osteoblasts showed no effect on HSC number and function [20]. These studies argue that osteoblasts may be dispensable for HSC maintenance and self-renewal. Interestingly, Bhatia et al. recently reported that osteoblast ablation did not result in a decrease in LTHSCs, but their long-term reconstitution and self-renewal capacities were impaired [33]. Tie-2-expressing HSCs could adhere to osteoblasts and stay in the quiescent state induced by angiopoietin-1 [34]. These data again suggest that osteoblasts play an important role in the regulation of
HSC self-renewal. Taken together, at present, osteoblasts remain the most controversial cellular component of the bone marrow niche. Apparently, more studies are needed to clarify these issues.

The nerve system seems to regulate HSCs, suggesting that HSCs are regulated systemically as well. In dopamine beta-hydroxylase-deficient mice, the G-CSF-triggered mobilization of HSCs was dramatically compromised, indicating that noradrenergic neurons were required for the mobilization of HSCs [35]. Nerves may also participate in HSCs' circadian fluctuation in the bloodstream. Sympathetic nerves can deliver adrenergic signals to down-regulate CXCL12 by decreasing the expression of Sp1 transcription factor, resulting in the daily egress of HSCs and progenitors into peripheral blood [36]. Nakauchi group claim that approximately $20 \%$ of HSCs are in direct contact with Schwann cells on the autonomic nerves. These Schwann cells may play a role in quiescent HSC maintenance by activating TGF- $\beta$ [37], suggesting that the nerve system is also a part of the niche component.

\section{Extracellular signals regulating HSCs}

In HSC niches, various soluble and membrane-bound proteins are supposed to participate in the regulation of HSC maintenance and self-renewal (Table 1; Fig. 3). Some signals may stimulate HSCs to cycle and expand the HSC number. In contrast, other signals may keep HSCs in the quiescent state to protect them from cellular damage and eradication. Some factors have pleiotropic effects. For instance, it was reported that CXCL12 was not only a chemoattractant for HSC homing or mobilization but also a regulator of HSC quiescence [38]. Here, we summarize candidate signals that have an important function in the self-renewal and differentiation of HSCs.

Table 1 Extracellular signals regulating HSC

\begin{tabular}{|c|c|c|c|c|}
\hline Ligand & Receptor & Research model & Effect on HSC & References \\
\hline SCF & c-Kit & $\begin{array}{l}\mathrm{W}^{41} / \mathrm{W}^{41} \text { mice } \\
\text { Anti-c-kit } \mathrm{mAbs}\end{array}$ & Support HSC survival & {$[41,121]$} \\
\hline TPO & Mpl & TPO/Mpl KO mice & Stimulate HSC regeneration & {$[51]$} \\
\hline CXCL12 & CXCR4 & Cxcr4 KO mice & Induce G0 HSCs & [38] \\
\hline TGF- $\beta$ & TGFbR & $\begin{array}{l}\text { Ex vivo culture } \\
\text { Tgfbr KO mice } \\
\text { Block TGF- } \beta \text { pathway after chemotherapy }\end{array}$ & $\begin{array}{l}\text { Inhibit HSC proliferation } \\
\text { Maintain G0 HSCs } \\
\text { Reestablish HSC dormancy after revival }\end{array}$ & $\begin{array}{l}{[56,58]} \\
{[37]} \\
{[63]}\end{array}$ \\
\hline IFN & IFNR & Ifnr KO mice & Wake up G0 HSCs & {$[68,72]$} \\
\hline Notch ligands & Notch1-4 & $\begin{array}{l}\text { Overexpression Notch pathway components } \\
\text { Rbpj gene KO mice }\end{array}$ & $\begin{array}{l}\text { Support HSC regeneration } \\
\text { No effect on HSCs }\end{array}$ & $\begin{array}{l}{[83,84]} \\
{[86]}\end{array}$ \\
\hline Ang-1 & Tie-2 & Culture and in vivo injection & Maintain G0 HSCs & {$[34]$} \\
\hline
\end{tabular}

Candidate extracellular signals that regulate HSCs are listed 

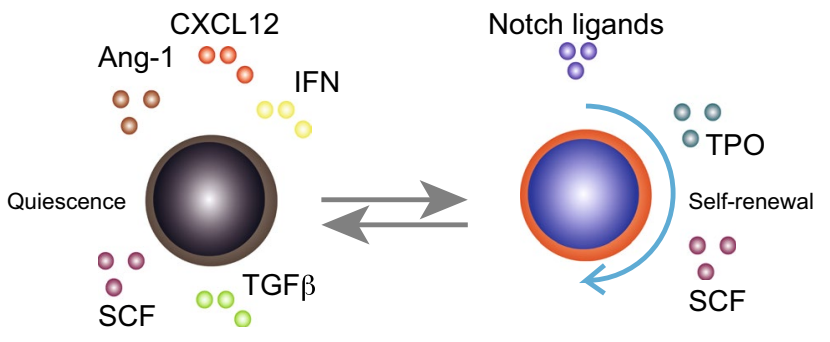

Fig. 3 G0 and self-renewal controls. In addition to molecules that maintain the G0 state or support self-renewal in HSCs, molecules are desired that drive HSCs into the cell cycle or revert HSCs back to the G0 state

SCF and thrombopoietin (TPO) are two fundamental cytokines for HSCs. SCF (also known as c-kit ligand, mast cell growth factor, or steel factor) can bind to the c-Kit receptor on HSCs to mediate its effects [39]. Studies of mutant mice in the $\mathrm{W}$ locus encoding the $c$-kit receptor or those using anti-c-Kit neutralizing antibody showed that the functional loss of c-Kit receptor led to the death of embryos with the elimination of HPCs and mature blood cells [40, 41]. In vitro culture of HSCs revealed the fundamental role of SCF in supporting the survival of HSCs [42, 43] and its synergism with a number of cytokines including interleukin-3, -6, -11, -12, and -27 and TPO [44, 45]. These early studies established the vital role of SCF and its receptor in the regulation of HSCs. Later, the partial inactivation of the $c$-kit receptor showed a reduced self-renewal capacity and loss of the quiescence state in adult HSCs [46]. It was also reported that a low level of c-Kit expression marks the most quiescent HSCs in adult mice [47], whereas c-Kithigh HSCs may originate from the c-Kit-low HSCs [48].

TPO is another critical cytokine that regulates HSCs, although TPO was originally cloned as a megakaryocyte factor. In vitro culture of HSCs suggested that TPO can efficiently expand the HSC pool if combined with SCF or IL-3 [49, 50]. Deleting TPO's receptor, $\mathrm{Mpl}$, in the HSCs resulted in reconstitution failure in irradiated mice [51]. The inactivation of TPO expression led to a fourfold increased requirement of normal bone marrow cells to rebuild the blood system in TPO-null recipients [52]. Interestingly, the increase of quiescent HSCs was also observed in TPO-null mice, suggesting that TPO may support the maintenance of quiescent HSCs [53, 54].

Various cell types express TGF- $\beta 1$, including megakaryocytes, macrophages, $\mathrm{T}$ cells, stromal cells, endothelial cells, and others [55]. A critical inhibitory role of TGF- $\beta$ in the regulation of HSCs and HPCs was suggested more than a decade ago $[56,57]$. Single-cell culture experiments also indicated that TGF- $\beta$ maintained the self-renewal capacity of single HSCs for up to 1 week $[58,59]$, but most initial studies were based on in vitro experiments.
TGF- $\beta$ signaling pathway knockout appeared to be embryonic lethal in mice [60]. Larsson et al. found that using a conditional knockout strategy, TGF- $\beta$ receptor 1-deficient HSCs exhibited a normal cell cycle and long-term repopulating capacity [61]. However, TGF- $\beta$ receptor 2 deficiency showed reduced repopulating activity [37]. When $\operatorname{Smad} 4$, a key signal molecule in common with various TGF- $\beta$ signaling pathways, was conditionally deleted, HSCs exhibited impaired self-renewal capacity and a reduced number of bone marrow cells [62]. These works indicate that the TGF- $\beta$ signaling pathway plays a role in the maintenance of quiescent HSCs. When mice were treated with 5-fluorouracil (5-FU) to induce a stress state in HSCs, the expression of TGF- $\beta$ increased significantly on days $11-15$ after 5-FU treatment. At this time point, the extensive expansion of HSCs and progenitors was predicted to restore the blood system. The blockade of the TGF- $\beta$ signal resulted in a faster hematopoietic regeneration, likely by forcing HSCs to undergo more cycles. This finding suggests that TGF- $\beta$ can reestablish the hibernation of HSCs to avoid their extensive exhaustion. Interestingly, the blockade of TGF- $\beta$ signaling in a normal state did not affect the cell cycle of HSCs, indicating that the effect of TGF- $\beta$ is context-determined by the emergent events [63]. Recently, Zhao et al. reported that the deletion of megakaryocytes resulted in the loss of quiescent HSCs due to the TGF- $\beta$ insufficiency. Interestingly, injecting TGF- $\beta$ into megakaryocyte-depleted mice can restore the HSCs' hibernation. Tgfbl knockout in megakaryocytes also resulted in a decrease in quiescent HSCs in bone marrow. HSC hibernation may be dependent on TGF- $\beta$, which is mostly produced by megakaryocytes [55].

Interferon (IFN) is a cytokine produced primarily in response to tumor cells or infection, especially viral infection [64]. In vitro studies demonstrated that IFN can suppress myeloid [65] or erythroid [66] colony formation. IFN- $\gamma$ could markedly reduce the number of B cells and myeloid progenitors in the bone marrow and spleen [67]. In contrast, IFN- $\alpha / \beta$ receptor inactivation in mice showed minor change in the progenitor cell number [64]. Recently, a positive effect of IFN signaling on HSCs was reported $[68,69]$. The injection of IFN- $\alpha$ into mice stimulated quiescent LT-HSCs to enter the cell cycle, making them susceptible to 5-FU. Long-term exposure to IFN- $\alpha$ led to the loss of HSC repopulating capacity [68]. Interferon regulatory factor-2 (IRF2) functions as the suppressor of the IFN signaling pathway [70]. Sato et al. found that IRF2 deletion led to a reduction in HSC reconstitution ability. Enhanced IFN signaling seemed to induce the exhaustion of HSCs. When IFN- $\alpha$ receptor was deleted in IRF2-deficient mice, a recovery of HSC reconstitution capacity was observed in Irf2-deficient HSCs. IFN- $\alpha$ can be considered a new player in the regulation of HSCs [69, 71]. 
IFN- $\gamma$ was also found to stimulate quiescent HSCs in vivo [72]. However, the culture of highly purified HSCs in vitro showed the suppressive effect of IFN- $\gamma$, and virus infection induced a delayed recovery of the HSC pool [73], consistent with in vitro culture data with progenitor cells $[64,67]$. More recently, Pietras et al. attempted to clarify this paradoxical effect of IFN on HSCs. They showed that a long-term exposure to IFN- $\alpha$ resulted in bone marrow aplasia. However, before HSC proliferation was suppressed, IFN- $\alpha$ transiently down-regulated the quiescence-enforcing genes, and a short duration HSC stimulation resulted in their expansion. Seemingly, once quiescent HSCs were awakened by IFN- $\alpha$, they lost their repopulating capacity upon returning to the quiescent state. This impairment of HSCs may be caused by the enhanced apoptosis trigged by IFN [74]. Together, these studies show that IFN has a complex effect on HSCs.

G-CSF was the first cytokine identified by molecular cloning, and it is used in clinics as an HSC mobilizing agent and a treatment for neutropenia. A number of studies have attempted to unveil the mechanism of HSC mobilization [75]. Interestingly, Schuettpelz et al. reported that G-CSF is involved in the regulation of HSC quiescence and expansion [76]. After mice were given G-CSF for 7 days, the absolute number of HSCs in the bone marrow increased. However, when expanded HSCs return to quiescence, they seem to lose their repopulating capacity in part due to the up-regulation of Toll-like receptor (TLR) signaling pathways. The deletion of My-D88, an adaptor protein required for most TLR signaling, attenuated the G-CSFinduced effect on HSCs [4]. More recently, Mouttie et al. reported that G-CSF could enhance autophagy in HSCs [77]. Autophagy was previously suggested to be required for HSC maintenance [78].

Notch signaling is a highly conserved pathway in various species. There are five ligands (D111, 3, and 4 and Jag 1,2) and four receptors in mammals (Notch 1-4). It is well known that Notch signaling is a crucial regulator in the development of HSCs and differentiation into myeloid cells, B cells, and T cells [79]. However, in adult hematopoiesis, the role of Notch signaling remains controversial. The in vitro culture of hematopoietic precursors with immobilized Notch ligands and other cytokines dramatically expands precursors capable of reconstituting the blood system for a short time [80]. The culture of HSCs with endothelial cells in vitro showed that the maintenance of endothelial cells and the expansion of HSCs are Notchdependent [81]. In addition to these in vitro culture studies, the constitutive expression of the intracellular domain of Notch1 immortalized HSCs [82] and expanded the HSC pool in vivo [83]. The overexpression of HES-1, a downstream effector of the notch receptor, showed a similar result of HSC proliferation [84]. These gain-of-function experiments suggest that Notch ligands play a critical role in the regulation of adult HSCs. However, Mancini et al. reported that the simultaneous deletion of Jagged1 and Notch1 in mice had no impact on the absolute number and dominant state in HSCs after repeated 5-FU administration. This study challenges the previous view of Notch's important role in HSC maintenance [85]. To eliminate the possibility of other Notch pathway components compensating for the deletion of Jagged 1 and Notch1, Maillard et al. performed a knock-in of a fusion protein called dominant-negative Mastermind-like1 construct, which could block the Notch1-4 pathway. No change in the frequency and repopulating capacity of HSCs was observed. Moreover, by deleting the Rbpj gene, which encodes the common DNA-binding factor for various Notch pathways, a normal number and function of HSCs was also observed [86]. To explain this paradox, this group further analyzed the Notch pathway activity and found that Notch-targeting genes were expressed at low levels. It is likely that under physiologic conditions, Notch signaling is activated at a very low level, and thus its role in adult HSCs is not so obvious [86]. Another group reported that in homeostasis, the Notch pathway is dispensable for HSC maintenance. Conversely, when they investigated the role of the Notch pathway in the stress state induced by irradiation or 5-FU, they found that Notch2 but not Notch1 was activated to enhance the regeneration of HSCs and HPCs [87]. The in vivo mapping of Notch receptor expression on various hematopoietic cell types showed that HSCs express more Notch2 than Notch1, indicating that distinct Notch ligands and receptors may regulate different cell types in hematopoiesis [88]. Taken together, in the regulation of adult HSCs, the Notch signaling pathway may play a role in emergency hematopoiesis.

\section{Transcription factors regulating HSCs}

Transcription factors (TFs) play a role in the fate determination of HSCs. Supporting this idea, a number of transcription factors have been found to be essential for selfrenewal in HSCs (Table 2). Scl-deficient HSCs exhibited impaired long-term activity with increased cycling HSCs [89]. Conditional pre-B cell leukemia transcription factor 1 (PBX1) deletion in HSCs impaired the self-renewal capacity in HSCs, as shown by secondary transplantation [90]. The overexpression of early growth response 1 (Egr1) in HSCs suppressed the differentiation into the granulocyte and erythroid lineages [91]. In contrast, Egr1 deletion leads to HSC proliferation but reduces the long-term reconstitution capacity in serial transplantation [92]. The loss of growth factor independent 1 (Gfi-1) could also result in impairment in the long-term reconstitution capacity of HSCs [93]. Some transcription factors may play distinct 
Table 2 Transcription factors regulating HSCs

\begin{tabular}{llll}
\hline Gene & Mouse model & Effect on HSC & References \\
\hline Scl & Scl $^{+-}$ & Maintain HSCs in G0 & {$[89]$} \\
Pbx-1 & Conditional KO $^{-}$ & Maintain self-renewal & {$[90]$} \\
Egr-1 & Egr1 $^{-/-}$ & Maintain HSCs in G0 & {$[92]$} \\
Gfi-1 & Gfi-1 $^{-/-}$ & Maintain HSCs in G0 & {$[93]$} \\
Evi-1 & Conditional KO $^{-}$ & Maintain self-renewal & {$[98]$} \\
PU.1 & Conditional KO & Maintain HSCs in G0 & {$[108]$} \\
FoxO & Conditional KO $^{-}$ & Maintain HSCs in G0 & {$[112,113]$} \\
Mef & Mef $^{--}$ & Wake up G0 HSCs & {$[117]$} \\
P53 & P53 $^{-/-}$ & Maintain HSCs in G0 & {$[119]$} \\
\hline
\end{tabular}

Candidate transcription factors that regulate HSCs are listed

roles in embryonic and adult hematopoiesis. For instance, runt-related transcription factor 1 (RUNX1) is essential for HSC development in embryos [94]. Conversely, RUNX1 is dispensable for the maintenance of adult HSCs [95, 96].

Ecotropic viral integration site 1 (Evi-1) is an oncogenic transcription factor of the SET/PR domain protein family, and it is predominantly expressed in both embryonic and adult HSCs [97]. Mouse embryos lacking Evi-1 die due to the remarkably decreased number and reconstitution capacity of HSCs. Conditional Evi-1 deletion in adult mice also showed that Evi-1 is essential for the maintenance of HSCs [98]. By knocking in an internal ribosome entry site (IRES)-GFP cassette into the Evi-1 locus, Kataoka et al. demonstrated that Evi-1 was predominantly expressed in LT-HSCs, and its expression was sharply down-regulated along with differentiation, indicating that the Evi-1 expression level is a candidate HSC-specific marker. The transplantation of GFP+Kit+Sca-1+Lineage- (KSL) cells showed a greater level of multi-lineage reconstitution compared with $\mathrm{GFP}^{-} \mathrm{KSL}$ cells, suggesting that Evi-1 plays a role in HSC self-renewal [99]. Gene expression microarray analysis revealed that Evi-1 can up-regulate "stemness" genes characteristic for LT-HSCs but down-regulated genes involved in DNA replication and DNA repair [100]. Taken together, these findings indicate that Evi-1 is an important regulator for $\mathrm{HSC}$ maintenance and self-renewal.

Transcription factors act on HSCs in a dose-dependent manner in a particular tissue but not in others. A haploid dose of GATA-2 reduced HSC generation in the aortagonad-mesonephros region, whereas it has a minimal impact on yolk sac, fetal liver, or adult bone marrow [101]. The transcription factor PU.1, a member of the E26 transformation-specific (ETS) family, is encoded by the protooncogene sfpi-1 [102] and dynamically expressed in the hematopoietic system from HSCs to differentiated cells [103].The expression of PU.1 is correlated along with the lineage commitment processes from HSCs to myeloid, macrophage, and lymphoid lineages [104, 105]. This differentiation regulation is dose-dependent; a high level of PU.1 expression favors differentiation to dendritic cells over differentiation to macrophages [106]. It also promotes macrophage differentiation more than granulocyte differentiation [107]. Conditional PU.1 deletion in adult mice showed that PU.1 was required by lymphoid and myeloid progenitors. There was no defect in the repopulating capacity of PU.1-deficient HSCs [104]. However, Staber et al. recently reported an elegant PU.1 study. A mutated gene sequence was knocked in an upstream regulatory element of PU.1. As a result, the auto-regulatory site of PU.1 was disrupted, leading to a half reduction of PU.1 messenger RNA. In serial competitive repopulating assays, these PU.1-reduced HSCs showed a severe impairment of HSC reconstitution capacity. These cells totally failed to reconstitute the bone marrow in the third transplantation. Chromatin Immunoprecipitation (ChIP) sequence data suggested that the reduction of PU.1 may stimulate active cycling, possibly resulting in the loss of HSCs [108].

Members of the FoxO transcription factor family (FoxO1, FoxO3, FoxO4, and FoxO6) are critical downstream effectors of the PI3K/AKT pathway and are involved in the regulation of cell cycle arrest, stress resistance, apoptosis, and differentiation, all of which are strongly associated with the function of HSCs [109]. Due to the possible functional redundancy between FoxO family members $[110,111]$, Tothov et al. developed a triple conditional deletion of FoxO1, FoxO3, and FoxO4 to evaluate the deficiency of FoxO family genes expressed in HSCs. In their research, the loss of FoxO increased the short-term reconstitution capacity but decreased the long-term reconstitution. It was suggested that this HSC phenotype might be caused by the aberrant accumulation of ROS in HSCs, which could be rescued by antioxidant treatment [112]. The conditional deletion of FoxO3a alone also showed a decreased reconstitution level by serial transplantation. FoxO3a-deficient HSCs showed more severe reduction in repopulating capacity upon aging [113]. Another research group reported a similar finding, suggesting that Foxo3 is the main player of the FoxO family in HSCs [114]. Warr et al. focused on cell autophagy in HSCs. They assumed that HSCs used autophagy to protect themselves from apoptosis induced by metabolic stress. In this self-rescue process, FoxO induced the expression of pro-autophagy genes in HSCs. FoxO3 expression with ongoing autophagy appeared to be required for the survival of aged HSCs [115]. Taken together, FoxO plays a pivotal role in G0 maintenance and stress resistance.

There are specific transcription factors that negatively regulate HSCs. Mef is also a member of the ETS family, whose expression level is dramatically repressed in human acute myeloid leukemia, suggesting that the down-regulation of Mef can stimulate the proliferation of leukemia cells 
[116]. Lacorazza et al. showed that in the absence of Mef, HSCs exhibited a significantly greater level of reconstitution potential in serial transplantation. Interestingly, Mefdeficient HSCs did not show any repopulation advantage over wild type HSCs in the primary transplantation, suggesting that Mef acts primarily on LT-HSCs [117].

More and more transcription factors and regulators have been reported to have effects on hematopoiesis. Now many researchers are trying to understand the framework of complex transcription regulation in hematopoiesis. For instance, PU.1 not only plays a role in HSC self-renewal but also antagonizes GATA1 at the lineage commitment to monocytes preventing differentiation to erythrocytes and megakaryocytes [118]. The p53 tumor suppressor gene could maintain the quiescence of HSCs via an interdependent relationship between MEF/ELF4 and p53. Furthermore, p53 may directly target the transcription factor Gfi-1 [119]. Likewise, to understand the normal and abnormal transcriptional regulation network in HSCs should be a goal of future work.

\section{Future challenges}

Both in vivo and in vitro studies have advantages. For instance, a physiological role can be studied in vivo, and a direct effect can be studied in vitro. In this regard, these different approaches are complementary. If we can have consistent data from in vivo and vitro studies, the findings are beyond controversy.

There are a number of studies that may have fallen into controversy because either an in vivo or in vitro study was performed to reach a conclusion, particularly in studies of soluble factors. A number of studies were extensively performed to understand the role of CXCL12. It is known that this chemoattractant is very important in the migration or mobilization of HSCs. CXCL12 is almost certainly one of the main niche factors for HSCs. However, few studies have ever successfully shown its significant in vitro effects [120]. How CXCL12 acts on HSCs and what CXCL12 actually does to HSCs remain to be answered. This also seems to be the case for IFN. If IFN can wake up quiescent HSCs, why do we barely see its effect on HSCs in vitro (ZW, unpublished data, 2015)? Perhaps we must wait for a new technology to be developed to explore the direct effects of these proteins on HSCs. Otherwise, we need to reconsider the possibility of their indirect effects in vivo.

The new view of hematopoiesis (Fig. 1) was a large surprise. However, it is difficult to understand some of the data [1]. For instance, how many HPCs are cycling at any time? If the cycling of many HPCs with different proliferation potentials is not synchronized, why can some HPCs not clonally and predominantly contribute to a significant portion of the pool of neutrophils? Nevertheless, analysis of red blood cells and platelets should be included to see whether these lineages are also maintained independent of HSCs. We need to understand more of what short, intermediate, and long-term HSCs do in developmental and aging processes because these HSCs may have different roles. In contrast, HPCs may have more self-renewal potential than we previously thought because they produce a huge number of blood cells in a short time. The maintenance of the G0 phase may also be important for HPCs. Soon after these issues are appropriately addressed, we may have to revise our concept of HSCs and HPCs. In addition, future work should continuously focus on the further clarification of known and as yet unknown regulators of HSC quiescence, self-renewal, and lineage commitment. A true understanding of HSCs provides vital knowledge and technology that can be applied to clinical therapies for many patients with hematological diseases.

Acknowledgments We thank Weiping Yuan, Fang Dong, Xiaofang Wang, Jinhong Wang, Haitao Bai, and Shanshan Zhang for their support and advice. This work was in part supported by Ministry of Science and Technology of China (2015CB964403 and 2015CB964404), National Natural Science Foundation of China (NSFC) (81470279), and Tianjin Foreign Expert Program.

\section{References}

1. Sun J, Ramos A, Chapman B, Johnnidis JB, Le L, Ho YJ, Klein A, Hofmann O, Camargo FD. Clonal dynamics of native haematopoiesis. Nature. 2014;514(7522):322-7.

2. Yamamoto R, Morita Y, Ooehara J, Hamanaka S, Onodera M, Rudolph KL, Ema H, Nakauchi H. Clonal analysis unveils selfrenewing lineage-restricted progenitors generated directly from hematopoietic stem cells. Cell. 2013;154(5):1112-26.

3. Ema H, Morita Y, Suda T. Heterogeneity and hierarchy of hematopoietic stem cells. Exp Hematol. 2014;42(2):74-82

4. Wilson A, Laurenti E, Oser G, van der Wath RC, Blanco-Bose W, Jaworski M, Offner S, Dunant CF, Eshkind L, Bockamp E, Lio P, Macdonald HR, Trumpp A. Hematopoietic stem cells reversibly switch from dormancy to self-renewal during homeostasis and repair. Cell. 2008;135(6):1118-29.

5. Bradford GB, Williams B, Rossi R, Bertoncello I. Quiescence, cycling, and turnover in the primitive hematopoietic stem cell compartment. Exp Hematol. 1997;25(5):445-53.

6. Cheshier SH, Morrison SJ, Liao X, Weissman IL. In vivo proliferation and cell cycle kinetics of long-term self-renewing hematopoietic stem cells. Proc Natl Acad Sci USA. 1999;96(6):3120-5.

7. Sudo K, Ema H, Morita Y, Nakauchi H. Age-associated characteristics of murine hematopoietic stem cells. J Exp Med. 2000;192(9):1273-80.

8. Qiu J, Papatsenko D, Niu X, Schaniel C, Moore K. Divisional history and hematopoietic stem cell function during homeostasis. Stem Cell Rep. 2014;2(4):473-90.

9. Harrison DE, Jordan CT, Zhong RK, Astle CM. Primitive hemopoietic stem cells: direct assay of most productive populations by competitive repopulation with simple 
binomial, correlation and covariance calculations. Exp Hematol. 1993;21(2):206-19.

10. Szilvassy SJ, Humphries RK, Lansdorp PM, Eaves AC, Eaves CJ. Quantitative assay for totipotent reconstituting hematopoietic stem cells by a competitive repopulation strategy. Proc Natl Acad Sci USA. 1990;87(22):8736-40.

11. Ema $H$, Nakauchi $H$. Expansion of hematopoietic stem cells in the developing liver of a mouse embryo. Blood. 2000;95(7):2284-8.

12. Ema H, Sudo K, Seita J, Matsubara A, Morita Y, Osawa M, Takatsu K, Takaki S, Nakauchi H. Quantification of selfrenewal capacity in single hematopoietic stem cells from normal and Lnk-deficient mice. Dev Cell. 2005;8(6):907-14.

13. Purton LE, Scadden DT. Limiting factors in murine hematopoietic stem cell assays. Cell Stem Cell. 2007;1(3):263-70.

14. Mendelson A, Frenette PS. Hematopoietic stem cell niche maintenance during homeostasis and regeneration. Nat Med. 2014;20(8):833-46.

15. Ema H, Suda T. Two anatomically distinct niches regulate stem cell activity. Blood. 2012;120(11):2174-81.

16. Schofield R. The relationship between the spleen colonyforming cell and the haemopoietic stem cell. Blood Cells. 1978;4(1-2):7-25.

17. Joseph C, Quach JM, Walkley CR, Lane SW, Lo Celso C, Purton LE. Deciphering hematopoietic stem cells in their niches: a critical appraisal of genetic models, lineage tracing, and imaging strategies. Cell Stem Cell. 2013;13(5):520-33.

18. Omatsu Y, Seike M, Sugiyama T, Kume T, Nagasawa T. Foxc1 is a critical regulator of haematopoietic stem/progenitor cell niche formation. Nature. 2014;508(7497):536-40.

19. Zhou BO, Yue R, Murphy MM, Peyer JG, Morrison SJ. Leptinreceptor-expressing mesenchymal stromal cells represent the main source of bone formed by adult bone marrow. Cell Stem Cell. 2014;15(2):154-68.

20. Ding L, Saunders TL, Enikolopov G, Morrison SJ. Endothelial and perivascular cells maintain haematopoietic stem cells. Nature. 2012;481(7382):457-62.

21. Pinho S, Lacombe J, Hanoun M, Mizoguchi T, Bruns I, Kunisaki Y, Frenette PS. PDGFRalpha and CD51 mark human nestin+ sphere-forming mesenchymal stem cells capable of hematopoietic progenitor cell expansion. J Exp Med. 2013;210(7):1351-67.

22. Mendez-Ferrer S, Michurina TV, Ferraro F, Mazloom AR, Macarthur BD, Lira SA, Scadden DT, Ma'ayan A, Enikolopov GN, Frenette PS. Mesenchymal and haematopoietic stem cells form a unique bone marrow niche. Nature. 2010;466(7308):829-34.

23. Ono N, Ono W, Mizoguchi T, Nagasawa T, Frenette PS, Kronenberg HM. Vasculature-associated cells expressing nestin in developing bones encompass early cells in the osteoblast and endothelial lineage. Dev Cell. 2014;29(3):330-9.

24. Ding L, Morrison SJ. Haematopoietic stem cells and early lymphoid progenitors occupy distinct bone marrow niches. Nature. 2013;495(7440):231-5.

25. Sugiyama T, Kohara H, Noda M, Nagasawa T. Maintenance of the hematopoietic stem cell pool by CXCL12-CXCR4 chemokine signaling in bone marrow stromal cell niches. Immunity. 2006;25(6):977-88.

26. Greenbaum A, Hsu YM, Day RB, Schuettpelz LG, Christopher MJ, Borgerding JN, Nagasawa T, Link DC. CXCL12 in early mesenchymal progenitors is required for haematopoietic stemcell maintenance. Nature. 2013;495(7440):227-30.

27. Kobayashi H, Butler JM, O’Donnell R, Kobayashi M, Ding BS, Bonner B, Chiu VK, Nolan DJ, Shido K, Benjamin L, Rafii S. Angiocrine factors from Akt-activated endothelial cells balance self-renewal and differentiation of haematopoietic stem cells. Nat Cell Biol. 2010;12(11):1046-56.
28. Kunisaki Y, Bruns I, Scheiermann C, Ahmed J, Pinho S, Zhang D, Mizoguchi T, Wei Q, Lucas D, Ito K, Mar JC, Bergman A, Frenette PS. Arteriolar niches maintain haematopoietic stem cell quiescence. Nature. 2013;502(7473):637-43.

29. Zhang J, Niu C, Ye L, Huang H, He X, Tong WG, Ross J, Haug J, Johnson T, Feng JQ, Harris S, Wiedemann LM, Mishina Y, Li L. Identification of the haematopoietic stem cell niche and control of the niche size. Nature. 2003;425(6960):836-41.

30. Calvi LM, Adams GB, Weibrecht KW, Weber JM, Olson DP, Knight MC, Martin RP, Schipani E, Divieti P, Bringhurst FR, Milner LA, Kronenberg HM, Scadden DT. Osteoblastic cells regulate the haematopoietic stem cell niche. Nature. 2003;425(6960):841-6.

31. Panaroni C, Tzeng YS, Saeed H, Wu JY. Mesenchymal progenitors and the osteoblast lineage in bone marrow hematopoietic niches. Curr Osteoporos Rep. 2014;12(1):22-32.

32. Visnjic D, Kalajzic Z, Rowe DW, Katavic V, Lorenzo J, Aguila HL. Hematopoiesis is severely altered in mice with an induced osteoblast deficiency. Blood. 2004;103(9):3258-64.

33. Bowers M, Zhang B, Ho Y, Agarwal P, Chen CC, Bhatia R. Osteoblast ablation reduces normal long-term hematopoietic stem cell self-renewal but accelerates leukemia development. Blood. 2015;125(17):2678-88.

34. Arai F, Hirao A, Ohmura M, Sato H, Matsuoka S, Takubo K, Ito K, Koh GY, Suda T. Tie2/angiopoietin-1 signaling regulates hematopoietic stem cell quiescence in the bone marrow niche. Cell. 2004;118(2):149-61.

35. Katayama Y, Battista M, Kao WM, Hidalgo A, Peired AJ, Thomas SA, Frenette PS. Signals from the sympathetic nervous system regulate hematopoietic stem cell egress from bone marrow. Cell. 2006;124(2):407-21.

36. Mendez-Ferrer S, Lucas D, Battista M, Frenette PS. Haematopoietic stem cell release is regulated by circadian oscillations. Nature. 2008;452(7186):442-7.

37. Yamazaki S, Ema H, Karlsson G, Yamaguchi T, Miyoshi H, Shioda S, Taketo MM, Karlsson S, Iwama A, Nakauchi H. Nonmyelinating schwann cells maintain hematopoietic stem cell hibernation in the bone marrow niche. Cell. 2011;147(5):1146-58.

38. Nie Y, Han YC, Zou YR. CXCR4 is required for the quiescence of primitive hematopoietic cells. J Exp Med. 2008;205(4):777-83.

39. Huang E, Nocka K, Beier DR, Chu TY, Buck J, Lahm HW, Wellner D, Leder P, Besmer P. The hematopoietic growth factor $\mathrm{KL}$ is encoded by the S1 locus and is the ligand of the c-kit receptor, the gene product of the W locus. Cell. 1990;63(1):225-33.

40. Geissler EN, McFarland EC, Russell ES. Analysis of pleiotropism at the dominant white-spotting (W) locus of the house mouse: a description of ten new W alleles. Genetics. 1981;97(2):337-61.

41. Ogawa M, Matsuzaki Y, Nishikawa S, Hayashi S, Kunisada T, Sudo T, Kina T, Nakauchi H, Nishikawa S. Expression and function of c-kit in hemopoietic progenitor cells. J Exp Med. 1991;174(1):63-71.

42. Carow CE, Hangoc G, Cooper SH, Williams DE, Broxmeyer HE. Mast cell growth factor (c-kit ligand) supports the growth of human multipotential progenitor cells with a high replating potential. Blood. 1991;78(9):2216-21.

43. Li CL, Johnson GR. Stem cell factor enhances the survival but not the self-renewal of murine hematopoietic long-term repopulating cells. Blood. 1994;84(2):408-14.

44. Muench MO, Schneider JG, Moore MA. Interactions among colony-stimulating factors, IL-1 beta, IL-6, and kit-ligand in the regulation of primitive murine hematopoietic cells. Exp Hematol. 1992;20(3):339-49. 
45. Metcalf D, Nicola NA. Direct proliferative actions of stem cell factor on murine bone marrow cells in vitro: effects of combination with colony-stimulating factors. Proc Natl Acad Sci USA. 1991;88(14):6239-43.

46. Thoren LA, Liuba K, Bryder D, Nygren JM, Jensen CT, Qian H, Antonchuk J, Jacobsen SEW. Kit regulates maintenance of quiescent hematopoietic stem cells. J Immunol. 2008;180(4):2045-53.

47. Matsuoka Y, Sasaki Y, Nakatsuka R, Takahashi M, Iwaki R, Uemura Y, Sonoda Y. Low level of c-kit expression marks deeply quiescent murine hematopoietic stem cells. Stem Cells. 2011;29(11):1783-91.

48. Shin JY, Hu W, Naramura M, Park CY. High c-Kit expression identifies hematopoietic stem cells with impaired self-renewal and megakaryocytic bias. J Exp Med. 2014;211(2):217-31.

49. Sitnicka E, Lin N, Priestley GV, Fox N, Broudy VC, Wolf NS, Kaushansky K. The effect of thrombopoietin on the proliferation and differentiation of murine hematopoietic stem cells. Blood. 1996;87(12):4998-5005.

50. Ema H, Takano H, Sudo $K$, Nakauchi $H$. In vitro selfrenewal division of hematopoietic stem cells. J Exp Med. 2000;192(9):1281-8.

51. Kimura S, Roberts AW, Metcalf D, Alexander WS. Hematopoietic stem cell deficiencies in mice lacking c-Mpl, the receptor for thrombopoietin. Proc Natl Acad Sci USA. 1998;95(3):1195-200.

52. Fox N, Priestley G, Papayannopoulou T, Kaushansky K. Thrombopoietin expands hematopoietic stem cells after transplantation. J Clin Invest. 2002;110(3):389-94.

53. Qian H, Buza-Vidas N, Hyland CD, Jensen CT, Antonchuk J, Mansson R, Thoren LA, Ekblom M, Alexander WS, Jacobsen SE. Critical role of thrombopoietin in maintaining adult quiescent hematopoietic stem cells. Cell Stem Cell. 2007;1(6):671-84.

54. Yoshihara H, Arai F, Hosokawa K, Hagiwara T, Takubo K, Nakamura Y, Gomei Y, Iwasaki H, Matsuoka S, Miyamoto K, Miyazaki H, Takahashi T, Suda T. Thrombopoietin/MPL signaling regulates hematopoietic stem cell quiescence and interaction with the osteoblastic niche. Cell Stem Cell. 2007;1(6):685-97.

55. Zhao M, Perry JM, Marshall H, Venkatraman A, Qian P, He XC, Ahamed J, Li L. Megakaryocytes maintain homeostatic quiescence and promote post-injury regeneration of hematopoietic stem cells. Nat Med. 2014;20(11):1321-6.

56. Keller JR, McNiece IK, Sill KT, Ellingsworth LR, Quesenberry PJ, Sing GK, Ruscetti FW. Transforming growth factor beta directly regulates primitive murine hematopoietic cell proliferation. Blood. 1990;75(3):596-602.

57. Sing GK, Keller JR, Ellingsworth LR, Ruscetti FW. Transforming growth factor beta selectively inhibits normal and leukemic human bone marrow cell growth in vitro. Blood. 1988;72(5):1504-11.

58. Yamazaki S, Iwama A, Takayanagi S, Eto $\mathrm{K}$, Ema $\mathrm{H}$, Nakauchi H. TGF-beta as a candidate bone marrow niche signal to induce hematopoietic stem cell hibernation. Blood. 2009;113(6):1250-6.

59. Sitnicka E, Ruscetti FW, Priestley GV, Wolf NS, Bartelmez SH. Transforming growth factor beta 1 directly and reversibly inhibits the initial cell divisions of long-term repopulating hematopoietic stem cells. Blood. 1996;88(1):82-8.

60. Oshima M, Oshima H, Taketo MM. TGF-beta receptor type II deficiency results in defects of yolk sac hematopoiesis and vasculogenesis. Dev Biol. 1996;179(1):297-302.

61. Larsson J. TGF- signaling-deficient hematopoietic stem cells have normal self-renewal and regenerative ability in vivo despite increased proliferative capacity in vitro. Blood. 2003;102(9):3129-35.
62. Karlsson G, Blank U, Moody JL, Ehinger M, Singbrant S, Deng CX, Karlsson S. Smad4 is critical for self-renewal of hematopoietic stem cells. J Exp Med. 2007;204(3):467-74.

63. Brenet F, Kermani P, Spektor R, Rafii S, Scandura JM. TGFbeta restores hematopoietic homeostasis after myelosuppressive chemotherapy. J Exp Med. 2013;210(3):623-39.

64. Binder D, Fehr J, Hengartner H, Zinkernagel RM. Virus-induced transient bone marrow aplasia: major role of interferon-alpha/ beta during acute infection with the noncytopathic lymphocytic choriomeningitis virus. J Exp Med. 1997;185(3):517-30.

65. Klimpel GR, Fleischmann WR Jr, Klimpel KD. Gamma interferon (IFN gamma) and IFN alpha/beta suppress murine myeloid colony formation (CFU-C)N: magnitude of suppression is dependent upon level of colony-stimulating factor (CSF). J Immunol. 1982;129(1):76-80.

66. Broxmeyer HE, Lu L, Platzer E, Feit C, Juliano L, Rubin BY. Comparative analysis of the influences of human gamma, alpha and beta interferons on human multipotential (CFU-GEMM), erythroid (BFU-E) and granulocyte-macrophage (CFU-GM) progenitor cells. J Immunol. 1983;131(3):1300-5.

67. Young HA, Klinman DM, Reynolds DA, Grzegorzewski KJ, Nii A, Ward JM, Winkler-Pickett RT, Ortaldo JR, Kenny JJ, Komschlies KL. Bone marrow and thymus expression of interferon-gamma results in severe B-cell lineage reduction, T-cell lineage alterations, and hematopoietic progenitor deficiencies. Blood. 1997;89(2):583-95.

68. Essers MAG, Offner S, Blanco-Bose WE, Waibler Z, Kalinke U, Duchosal MA, Trumpp A. IFN $\alpha$ activates dormant haematopoietic stem cells in vivo. Nature. 2009;458(7240):904-8.

69. Sato T, Onai N, Yoshihara H, Arai F, Suda T, Ohteki T. Interferon regulatory factor- 2 protects quiescent hematopoietic stem cells from type I interferon-dependent exhaustion. Nat Med. 2009;15(6):696-700.

70. Hida S, Ogasawara K, Sato K, Abe M, Takayanagi H, Yokochi T, Sato T, Hirose S, Shirai T, Taki S, Taniguchi T. CD8(+) T cell-mediated skin disease in mice lacking IRF-2, the transcriptional attenuator of interferon-alpha/beta signaling. Immunity. 2000;13(5):643-55.

71. Passegue E, Ernst P. IFN-alpha wakes up sleeping hematopoietic stem cells. Nat Med. 2009;15(6):612-3.

72. Baldridge MT, King KY, Boles NC, Weksberg DC, Goodell MA. Quiescent haematopoietic stem cells are activated by IFN-gamma in response to chronic infection. Nature. 2010;465(7299):793-7.

73. de Bruin AM, Demirel O, Hooibrink B, Brandts CH, Nolte MA. Interferon-gamma impairs proliferation of hematopoietic stem cells in mice. Blood. 2013;121(18):3578-85.

74. Pietras EM, Lakshminarasimhan R, Techner JM, Fong S, Flach $\mathrm{J}$, Binnewies M, Passegue E. Re-entry into quiescence protects hematopoietic stem cells from the killing effect of chronic exposure to type I interferons. J Exp Med. 2014;211(2):245-62.

75. Bendall LJ, Bradstock KF. G-CSF: from granulopoietic stimulant to bone marrow stem cell mobilizing agent. Cytokine Growth Factor Rev. 2014;25(4):355-67.

76. Schuettpelz LG, Borgerding JN, Christopher MJ, Gopalan PK, Romine MP, Herman AC, Woloszynek JR, Greenbaum AM, Link DC. G-CSF regulates hematopoietic stem cell activity, in part, through activation of Toll-like receptor signaling. Leukemia. 2014;28(9):1851-60.

77. Leveque-El Mouttie L, Vu T, Lineburg KE, Kuns RD, Bagger FO, Teal BE, Lor M, Boyle GM, Bruedigam C, Mintern JD, Hill GR, MacDonald KP, Lane SW. Autophagy is required for stem cell mobilization by G-CSF. Blood. 2015;125(19):2933-6.

78. Mortensen M, Soilleux EJ, Djordjevic G, Tripp R, Lutteropp M, Sadighi-Akha E, Stranks AJ, Glanville J, Knight S, Jacobsen SE, Kranc KR, Simon AK. The autophagy protein Atg7 is 
essential for hematopoietic stem cell maintenance. J Exp Med. 2011;208(3):455-67.

79. Kumano K, Chiba S, Kunisato A, Sata M, Saito T, NakagamiYamaguchi E, Yamaguchi T, Masuda S, Shimizu K, Takahashi T, Ogawa S, Hamada Y, Hirai H. Notch1 but not Notch2 is essential for generating hematopoietic stem cells from endothelial cells. Immunity. 2003;18(5):699-711.

80. Varnum-Finney B, Brashem-Stein C, Bernstein ID. Combined effects of Notch signaling and cytokines induce a multiple log increase in precursors with lymphoid and myeloid reconstituting ability. Blood. 2003;101(5):1784-9.

81. Butler JM, Nolan DJ, Vertes EL, Varnum-Finney B, Kobayashi H, Hooper AT, Seandel M, Shido K, White IA, Kobayashi M, Witte L, May C, Shawber C, Kimura Y, Kitajewski J, Rosenwaks Z, Bernstein ID, Rafii S. Endothelial cells are essential for the self-renewal and repopulation of Notch-dependent hematopoietic stem cells. Cell Stem Cell. 2010;6(3):251-64.

82. Varnum-Finney B, Xu L, Brashem-Stein C, Nourigat C, Flowers D, Bakkour S, Pear WS, Bernstein ID. Pluripotent, cytokinedependent, hematopoietic stem cells are immortalized by constitutive Notch1 signaling. Nat Med. 2000;6(11):1278-81.

83. Stier S, Cheng T, Dombkowski D, Carlesso N, Scadden DT. Notch1 activation increases hematopoietic stem cell selfrenewal in vivo and favors lymphoid over myeloid lineage outcome. Blood. 2002;99(7):2369-78.

84. Kunisato A, Chiba S, Nakagami-Yamaguchi E, Kumano K, Saito T, Masuda S, Yamaguchi T, Osawa M, Kageyama R, Nakauchi H, Nishikawa M, Hirai H. HES-1 preserves purified hematopoietic stem cells ex vivo and accumulates side population cells in vivo. Blood. 2003;101(5):1777-83.

85. Mancini SJ, Mantei N, Dumortier A, Suter U, MacDonald HR, Radtke F. Jagged1-dependent Notch signaling is dispensable for hematopoietic stem cell self-renewal and differentiation. Blood. 2005;105(6):2340-2.

86. Maillard I, Koch U, Dumortier A, Shestova O, Xu L, Sai H, Pross SE, Aster JC, Bhandoola A, Radtke F, Pear WS. Canonical notch signaling is dispensable for the maintenance of adult hematopoietic stem cells. Cell Stem Cell. 2008;2(4):356-66.

87. Varnum-Finney B, Halasz LM, Sun M, Gridley T, Radtke F, Bernstein ID. Notch2 governs the rate of generation of mouse long- and short-term repopulating stem cells. J Clin Invest. 2011;121(3):1207-16.

88. Oh P, Lobry C, Gao J, Tikhonova A, Loizou E, Manent J, van Handel B, Ibrahim S, Greve J, Mikkola H, ArtavanisTsakonas S, Aifantis I. In vivo mapping of notch pathway activity in normal and stress hematopoiesis. Cell Stem Cell. 2013;13(2):190-204.

89. Lacombe J, Herblot S, Rojas-Sutterlin S, Haman A, Barakat $\mathrm{S}$, Iscove NN, Sauvageau G, Hoang T. Scl regulates the quiescence and the long-term competence of hematopoietic stem cells. Blood. 2010;115(4):792-803.

90. Ficara F, Murphy MJ, Lin M, Cleary ML. Pbx1 regulates selfrenewal of long-term hematopoietic stem cells by maintaining their quiescence. Cell Stem Cell. 2008;2(5):484-96.

91. Krishnaraju K, Hoffman B, Liebermann DA. Early growth response gene 1 stimulates development of hematopoietic progenitor cells along the macrophage lineage at the expense of the granulocyte and erythroid lineages. Blood. 2001;97(5):1298-305.

92. Min IM, Pietramaggiori G, Kim FS, Passegue E, Stevenson KE, Wagers AJ. The transcription factor EGR1 controls both the proliferation and localization of hematopoietic stem cells. Cell Stem Cell. 2008;2(4):380-91.

93. Hock H, Hamblen MJ, Rooke HM, Schindler JW, Saleque S, Fujiwara Y, Orkin SH. Gfi-1 restricts proliferation and preserves functional integrity of haematopoietic stem cells. Nature. 2004;431(7011):1002-7.

94. Okuda T, van Deursen J, Hiebert SW, Grosveld G, Downing JR. AML1, the target of multiple chromosomal translocations in human leukemia, is essential for normal fetal liver hematopoiesis. Cell. 1996;84(2):321-30.

95. Ichikawa M, Asai T, Saito T, Seo S, Yamazaki I, Yamagata T, Mitani K, Chiba S, Ogawa S, Kurokawa M, Hirai H. AML-1 is required for megakaryocytic maturation and lymphocytic differentiation, but not for maintenance of hematopoietic stem cells in adult hematopoiesis. Nat Med. 2004;10(3):299-304.

96. Growney JD, Shigematsu H, Li Z, Lee BH, Adelsperger J, Rowan R, Curley DP, Kutok JL, Akashi K, Williams IR, Speck NA, Gilliland DG. Loss of Runx1 perturbs adult hematopoiesis and is associated with a myeloproliferative phenotype. Blood. 2005;106(2):494-504.

97. Yuasa H, Oike Y, Iwama A, Nishikata I, Sugiyama D, Perkins A, Mucenski ML, Suda T, Morishita K. Oncogenic transcription factor Evi1 regulates hematopoietic stem cell proliferation through GATA-2 expression. EMBO J. 2005;24(11):1976-87.

98. Goyama S, Yamamoto G, Shimabe M, Sato T, Ichikawa M, Ogawa S, Chiba S, Kurokawa M. Evi-1 is a critical regulator for hematopoietic stem cells and transformed leukemic cells. Cell Stem Cell. 2008;3(2):207-20.

99. Kataoka K, Sato T, Yoshimi A, Goyama S, Tsuruta T, Kobayashi $\mathrm{H}$, Shimabe M, Arai S, Nakagawa M, Imai Y, Kumano K, Kumagai K, Kubota N, Kadowaki T, Kurokawa M. Evi1 is essential for hematopoietic stem cell self-renewal, and its expression marks hematopoietic cells with long-term multilineage repopulating activity. J Exp Med. 2011;208(12):2403-16.

100. Kustikova OS, Schwarzer A, Stahlhut M, Brugman MH, Neumann T, Yang M, Li Z, Schambach A, Heinz N, Gerdes S, Roeder I, Ha TC, Steinemann D, Schlegelberger B, Baum C. Activation of Evi1 inhibits cell cycle progression and differentiation of hematopoietic progenitor cells. Leukemia. 2013;27(5):1127-38.

101. Ling KW, Ottersbach K, van Hamburg JP, Oziemlak A, Tsai FY, Orkin SH, Ploemacher R, Hendriks RW, Dzierzak E. GATA-2 plays two functionally distinct roles during the ontogeny of hematopoietic stem cells. J Exp Med. 2004;200(7):871-82.

102. Goebl MK. The PU.1 transcription factor is the product of the putative oncogene Spi-1. Cell. 1990;61(7):1165-6.

103. Back J, Allman D, Chan S, Kastner P. Visualizing PU.1 activity during hematopoiesis. Exp Hematol. 2005;33(4):395-402.

104. Dakic A, Metcalf D, Di Rago L, Mifsud S, Wu L, Nutt SL. PU.1 regulates the commitment of adult hematopoietic progenitors and restricts granulopoiesis. J Exp Med. 2005;201(9):1487-502.

105. Chang HC, Sehra S, Goswami R, Yao W, Yu Q, Stritesky GL, Jabeen R, McKinley C, Ahyi AN, Han L, Nguyen ET, Robertson MJ, Perumal NB, Tepper RS, Nutt SL, Kaplan MH. The transcription factor PU.1 is required for the development of IL9-producing $\mathrm{T}$ cells and allergic inflammation. Nat Immunol. 2010;11(6):527-34.

106. Bakri Y, Sarrazin S, Mayer UP, Tillmanns S, Nerlov C, Boned A, Sieweke MH. Balance of MafB and PU.1 specifies alternative macrophage or dendritic cell fate. Blood. 2005;105(7):2707-16.

107. Dahl R, Walsh JC, Lancki D, Laslo P, Iyer SR, Singh H, Simon MC. Regulation of macrophage and neutrophil cell fates by the PU.1:C/EBPalpha ratio and granulocyte colony-stimulating factor. Nat Immunol. 2003;4(10):1029-36.

108. Staber PB, Zhang P, Ye M, Welner RS, Nombela-Arrieta C, Bach C, Kerenyi M, Bartholdy BA, Zhang H, Alberich-Jorda M, Lee S, Yang H, Ng F, Zhang J, Leddin M, Silberstein LE, Hoefler G, Orkin SH, Gottgens B, Rosenbauer F, Huang G, Tenen DG. Sustained PU.1 levels balance cell-cycle regulators 
to prevent exhaustion of adult hematopoietic stem cells. Mol Cell. 2013;49(5):934-46.

109. Greer EL, Brunet A. FOXO transcription factors at the interface between longevity and tumor suppression. Oncogene. 2005;24(50):7410-25.

110. Furuyama T, Kitayama K, Shimoda Y, Ogawa M, Sone K, Yoshida-Araki K, Hisatsune H, Nishikawa S, Nakayama K, Nakayama K, Ikeda K, Motoyama N, Mori N. Abnormal angiogenesis in Foxo1 (Fkhr)-deficient mice. J Biol Chem. 2004;279(33):34741-9.

111. Lin L, Hron JD, Peng SL. Regulation of NF-kappaB, Th activation, and autoinflammation by the forkhead transcription factor Foxo3a. Immunity. 2004;21(2):203-13.

112. Tothova Z, Kollipara R, Huntly BJ, Lee BH, Castrillon DH, Cullen DE, McDowell EP, Lazo-Kallanian S, Williams IR, Sears C, Armstrong SA, Passegue E, DePinho RA, Gilliland DG. FoxOs are critical mediators of hematopoietic stem cell resistance to physiologic oxidative stress. Cell. 2007;128(2):325-39.

113. Miyamoto K, Araki KY, Naka K, Arai F, Takubo K, Yamazaki $\mathrm{S}$, Matsuoka S, Miyamoto $\mathrm{T}$, Ito $\mathrm{K}$, Ohmura $\mathrm{M}$, Chen $\mathrm{C}$, Hosokawa K, Nakauchi H, Nakayama K, Nakayama KI, Harada M, Motoyama N, Suda T, Hirao A. Foxo3a is essential for maintenance of the hematopoietic stem cell pool. Cell Stem Cell. 2007;1(1):101-12.

114. Yalcin S, Zhang X, Luciano JP, Mungamuri SK, Marinkovic D, Vercherat C, Sarkar A, Grisotto M, Taneja R, Ghaffari S. Foxo3 is essential for the regulation of ataxia telangiectasia mutated and oxidative stress-mediated homeostasis of hematopoietic stem cells. J Biol Chem. 2008;283(37):25692-705.
115. Warr MR, Binnewies M, Flach J, Reynaud D, Garg T, Malhotra R, Debnath J, Passegue E. FOXO3A directs a protective autophagy program in haematopoietic stem cells. Nature. 2013;494(7437):323-7.

116. Fukushima T, Miyazaki Y, Tsushima H, Tsutsumi C, Taguchi J, Yoshida S, Kuriyama K, Scadden D, Nimer S, Tomonaga M. The level of MEF but not ELF-1 correlates with FAB subtype of acute myeloid leukemia and is low in good prognosis cases. Leuk Res. 2003;27(5):387-92.

117. Lacorazza HD, Yamada T, Liu Y, Miyata Y, Sivina M, Nunes J, Nimer SD. The transcription factor MEF/ELF4 regulates the quiescence of primitive hematopoietic cells. Cancer Cell. 2006;9(3):175-87.

118. Chou ST, Khandros E, Bailey LC, Nichols KE, Vakoc CR, Yao Y, Huang Z, Crispino JD, Hardison RC, Blobel GA, Weiss MJ. Graded repression of PU.1/Sfpil gene transcription by GATA factors regulates hematopoietic cell fate. Blood. 2009;114(5):983-94.

119. Liu Y, Elf SE, Miyata Y, Sashida G, Liu Y, Huang G, Di Giandomenico S, Lee JM, Deblasio A, Menendez S, Antipin J, Reva B, Koff A, Nimer SD. p53 regulates hematopoietic stem cell quiescence. Cell Stem Cell. 2009;4(1):37-48.

120. Lai CY, Yamazaki S, Okabe M, Suzuki S, Maeyama Y, Iimura Y, Onodera M, Kakuta S, Iwakura Y, Nojima M, Otsu M, Nakauchi H. Stage-specific roles for CXCR4 signaling in murine hematopoietic stem/progenitor cells in the process of bone marrow repopulation. Stem Cells. 2014;32(7):1929-42.

121. Bowie MB, Kent DG, Copley MR, Eaves CJ. Steel factor responsiveness regulates the high self-renewal phenotype of fetal hematopoietic stem cells. Blood. 2007;109(11):5043-8. 